\title{
EfFect of Clearance AND Friction in REVOLUTE IMPERFECT JOINTS ON DYNAMIC Behaviors of a Slider-CranK Mechanism With Two SLIDERS
}

\author{
Ngoc-Thai HUYNH ${ }^{1}$, Thanh-Phong DAO ${ }^{2,3, *}$, Tuan-Hai NGUYEN ${ }^{1}$, \\ Hoang-Nghien $V U^{1}$, Le-Quang-Nhat HOANG ${ }^{1}$, Ho NGUYEN ${ }^{1}$ \\ ${ }^{1}$ Faculty of Electrical, Electronic, Mechanical and Construction, \\ Dong Nai Technology University, Vietnam \\ ${ }^{2}$ Division of Computational Mechatronics, Institute for Computational Science, \\ Ton Duc Thang University, Ho Chi Minh City, Vietnam \\ ${ }^{3}$ Faculty of Electrical \& Electronics Engineering, \\ Ton Duc Thang University, Ho Chi Minh City, Vietnam
}

*Corresponding Author: Thanh Phong DAO (email: daothanhphong@tdt.edu.vn) (Received: 30-September-2017; accepted: 03-January-2018; published: 31-March-2018)

DOI: http://dx.doi.org/10.25073/jaec.201821.73

\begin{abstract}
To increase the productivity of machining process, a two slider crank mechanism is proposed in this paper. In general, friction and clearance always present in any mechanical system. Hence, the effects of friction and clearance on a dynamic system are so critical. This paper aims to investigate their effects on the dynamic response of a slider-crank mechanism with two sliders and imperfect joints. Firstly, the mechanism is created in Solidworks and then it is simulated via finite element method in ANSYS. The dynamic simulation is conducted to evaluate the mentioned effects. The results revealed that the effect degree of clearance on the dynamic behaviors of the proposed mechanisms is significantly higher than that of friction. Also, the results indicated that the velocities, acceleration, and contact force graph are almost same at different friction coefficient. However, compared with ideal joint case, they had a maximum value and an unstable oscillation. This problem is due to journal collide into bearing induced the maximum values of contact force.
\end{abstract}

\section{Keywords}

Dynamic, radius of journal, friction coefficient, revolute imperfect joints, two sliders.

\section{Introduction}

There are significant factors that cause a low mechanical accuracy for a mechanical system. First, a clearance in a revolute joint is not evitable due to manufacturing and assembly tolerances, etc. The clearance causes undesired vibration and abrasion of the joint and increase the clearance. Second, the friction leads to an abrasion and a deformation of the joint. Moreover, the clearance size causes a contact-impact force in the revolute joint, which leads to a low accuracy in the mechanical system. The impact force also causes an abrasion joint and increases the clearance. Moreover, the different driving speed influences on the dynamic behaviors. 
Recently, a lot of researchers have been a great interest in on resolving challenging problems for dynamic responses of a mechanical system. For example, some focused on the contact force models [1, their results compared with the experimental data at the different clearance and driving speed. Besides, the flexible components and two clearance joints also were considered [2] where the wear prediction and optimization of maximum allowable wear occurred at the same number of rotation cycles for two clearance joints, simultaneously. Moreover, the effect of multiple clearance joints on dynamic of planar multibody mechanical system were analyzed and presented [3], in which three were motion phases of journal as: free motion, contact motion and impact motion, comparison between ideal joint and one clearance joint, two clearances, three clearances joint. In order to restrict clearance joint effects, a compliant mechanism or flexible mechanism was revealed based Taguchi method [4. However, the different material characteristic between journal and bearing causes friction force lead to joint wear and then induced damage for mechanical systems as reported [5] which influences of restitution coefficient and material characteristic cannot be ignored. Influences of clearance size and friction on the planar slidercrank mechanism with a clearance joint were considered by Bai and Zhao [6]. In addition, PSO algorithm was used to optimize the dynamics of a slider-crank mechanism with a clearance joint by Varedi [7]. The mixed lubrication model in revolute clearance joint was used to reduce friction by Zhao [8, 9].

During operation of the machining process, the productivity for machining the surface of a workpiece is one of the most important performance index. Almost previous studies have focused on designing and analyzing for one slider crank mechanism. However, for enhancing the manufacturing efficiency, there is a real requirements for a multiple-slider crank mechanism. Actually, the existing machining machines have worked based one cut tool that leads to low performances. Instead of using one slider crank mechanism, a two slider crank mechanism is proposed in this paper in order to increase number of cut tools and productivity for the planning machine.
The novelty of the present paper is to propose a innovative design for new slider crank mechanism with two sliders. Regarding a high effective motion of turning, milling, and drilling machines for machining process of removing undesired materials, a slider-crank mechanism with two sliders is proposed to practitioner, engineer, academics, and industry.

The objectives of this paper are to design and evaluate effects of clearance and friction on the dynamic of slider-crank mechanism with two sliders. Dynamic simulations are analyzed by using the finite element analysis in ANSYS.

\section{Modeling}

\subsection{Description of a slider-crank mechanism}

The slider-crank mechanism with two sliders and seven revolute clearance joint was used to analyze. The prototype of mechanism was shown in Fig. 1. The mechanism consisted of the rigid links namely (1) the 1st connecting rod, (2) the second connecting rod, (3) the first ray, (4) the first slider, (5) the second ray, (6) crank, (7) motor, (8) Base, (9) the second slider, (10) Rotation of motor control; (11) DC.

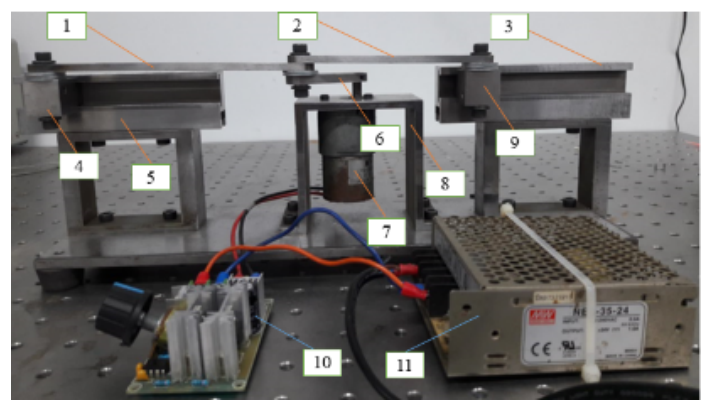

Fig. 1: Rigid Sider-crank Mechanism.

(1). The 1st connecting rod; (2). The 2 nd connecting rod; (3). The 1st ray; (4). The 1st slier; (5). The 2nd ray; (6). Crank; (7). Motor; (8). Base; (9). The 2nd slider; (10). Rotation of motor control; (11). DC 


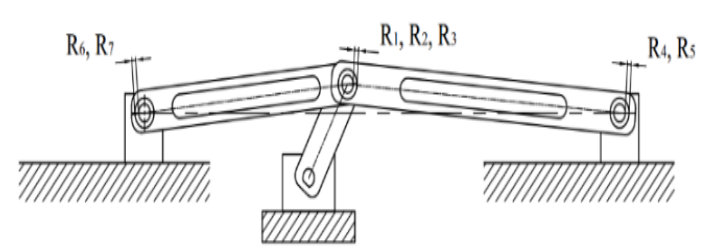

Fig. 2: Planar Slider-crank mechanism with revolute clearance joints.

Tab. 1: Simulations characteristics.

\begin{tabular}{|c|c|}
\hline Simulations characteristics & Value \\
\hline Modulus of elasticity $(\mathrm{GPa})$ & 200 \\
\hline Density $(\mathrm{kg} / \mathrm{m} 3)$ & 7850 \\
\hline Poisson's ratio & 0.3 \\
\hline Initial length of crank (mm) & 50 \\
\hline Length of the 1st connecting rod $(\mathrm{mm})$ & 180 \\
\hline Length of the 2nd connecting rod $(\mathrm{mm})$ & 140 \\
\hline Mass of crank $(\mathrm{kg})$ & 0.03 \\
\hline Mass of the 1st connecting rod $(\mathrm{kg})$ & 0.349 \\
\hline Mass of the 2nd connecting rod (kg) & 0.279 \\
\hline Mass of the 1st and 2nd slider (kg) & 0.192 \\
\hline
\end{tabular}

In order to capture the clearance in revolute, Fig. 2 depicts a scheme of a planar slider-crank mechanism with two sliders. It includes revolute clearance joints R1, R2 and R3 exist between crank, the first connecting rod and the second connecting rod, two revolute clearance joints R4 and R5 exist between the first connecting rod and first slider, two revolute clearance joints R6 and R7 exist between the second connecting rod and the second slider, one ideal revolute joint exist between base and motor shaft, and two translations joint $\mathrm{T} 1$ and $\mathrm{T} 2$ exist between the first ray and the first slider, between the 2 nd ray and the 2 nd slider.

These parameters were listed in Tab. 1. The crank is fixed to motor shaft. Two sliders are driven from motor shaft's rotation through the crank, the 1st connecting rod and second connecting rod to the 1 st slider and the 2 nd slider; turn the crank's rotation into linear motion of the first slider and the second slider.

\subsection{Revolute clearance joint model}

In general, two bodies are linked by joint, which is called journal bearing. The infect joint always has clearance. The imperfect joint as depicted in Fig. 3, the radial clearance is determined as follows:

$$
c=r_{B}-r_{j}
$$

where $r_{B}, r_{j}$ are the radii of bearing and journal, respectively.

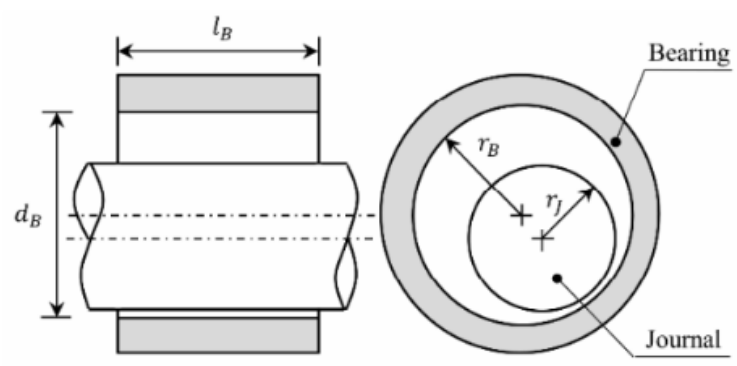

Fig. 3: Revolute joint with clearance.

\subsection{Results and discussion}

Initially, the center of journal and bearing are concentric. The crank assembles to motor shaft and is set up at horizontal position. The distance from the motor shaft center to the center of two sliders is $20 \mathrm{~mm}$ respect to vertical direction. Two sliders are driven by motor shaft's rotation through the crank, the first connecting rod and the second connecting rod to the first slider and the second slider; turn the crank's rotation into linear motion of the first slider and the second slider. The motor shaft rotates with constant rotation velocity $500 \mathrm{rpm}$, and radius of clearance is constant $0.25 \mathrm{~mm}$ in simulation duration 1 second and time step 10-4s at different friction coefficient in revolute clearance joints R1 to R7 compared with ideal joint. The joins: three Fixed- Ground, one fixed crank to 
shaft motor, seven revolute clearance joints, one revolute ideal joint base to shaft motor and two translation joints were created as in Fig. 4. Then input joint rotational velocity $500 \mathrm{rpm}$. The results of simulation as shown in Fig. 5.15.

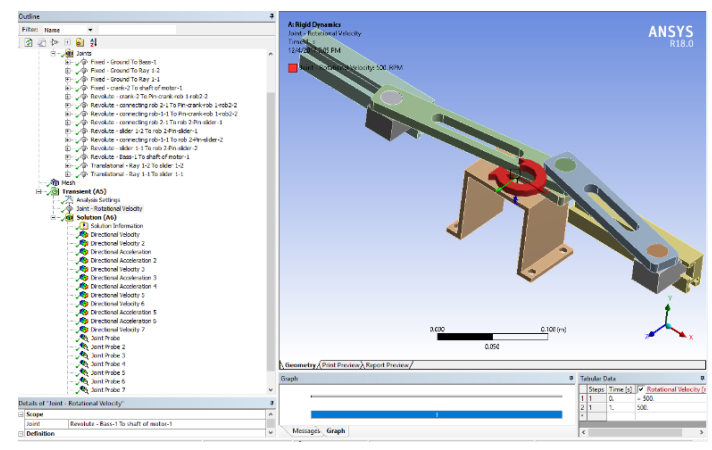

Fig. 4: Set up silulation in ANSYS.

The velocities of two sliders graph are depicted in Fig. 5. Its is identified that velocities are less affected by gap and friction. Because the curve of velocities has slightly effected and compared with to the ideal joint case when friction coefficient increase from 0.01 to 0.05 . The problem as presented in reference [2]. The same phenomena as presented in Fig. 7. 8 . It is the velocities of two connecting rods.

The accelerations of two sliders were pointed out in Fig. 6. Its revealed that accelerations were importantly affected by the gap because the graph shaked with hight peaks. The problem is due to journal suddenly impact into bearing induced the contact forces which draw out in Fig. 11 15. The same phenomena as shown in Fig. 9 10 It is the acceleration of two connecting rods. The problem was investigated in reference [1, 3, 5].

Fig. 12, 15 are the contact force in revolute imperfect joints and translaion joint. they proved this force is suddenly increased and vibrated with the maximum value compared with the ideal joint case. This problem was reported in reference [1, 3, 5].

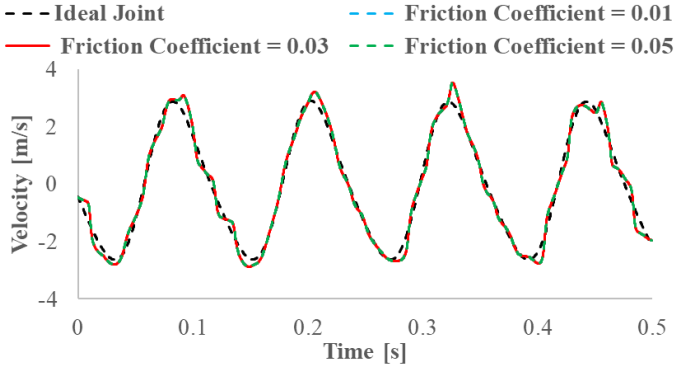

(a) The $1^{\text {st }}$ slider.

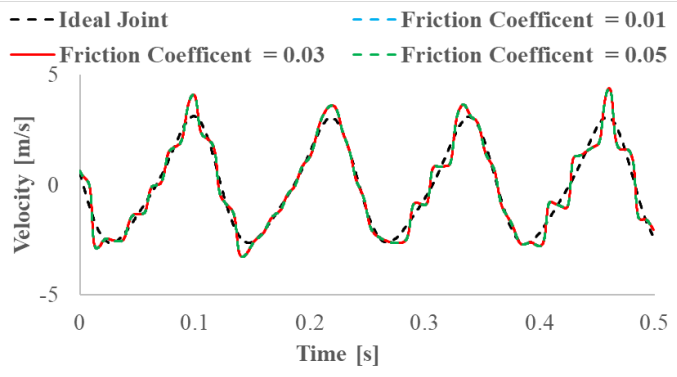

(b) The $2^{\text {nd }}$ slider.

Fig. 5: Velocity of two sliders.

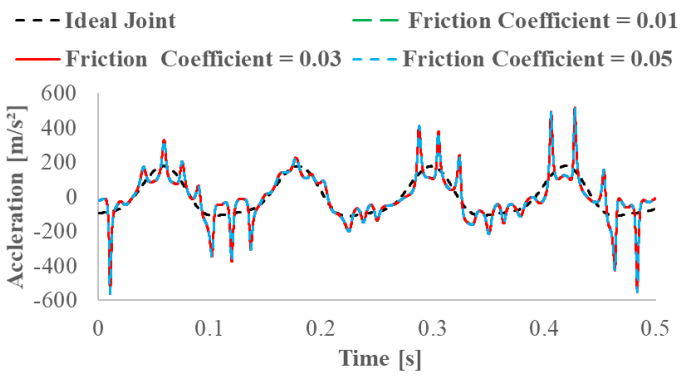

(a) The $1^{\text {st }}$ slider.

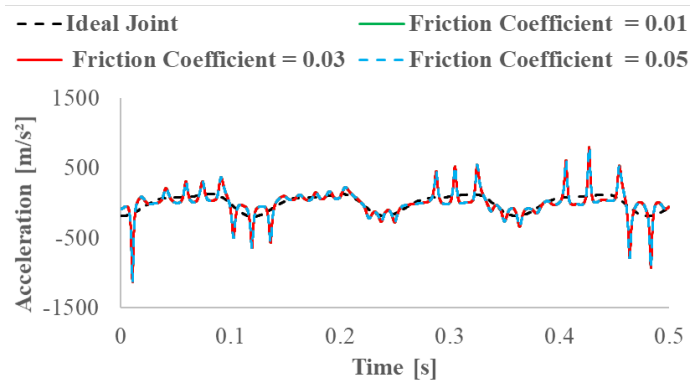

(b) The $2^{\text {nd }}$ slider.

Fig. 6: Acceleration of two sliders. 


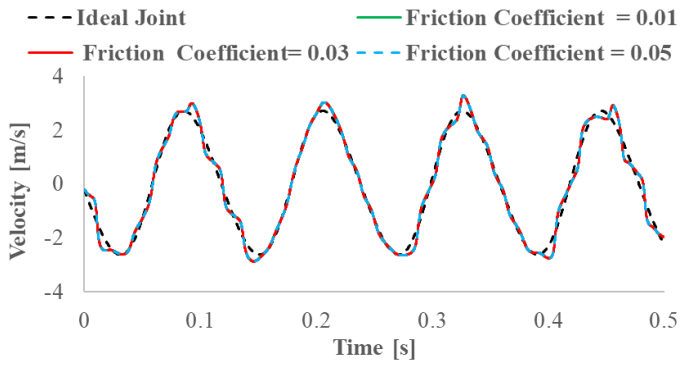

(a) X-velocity.

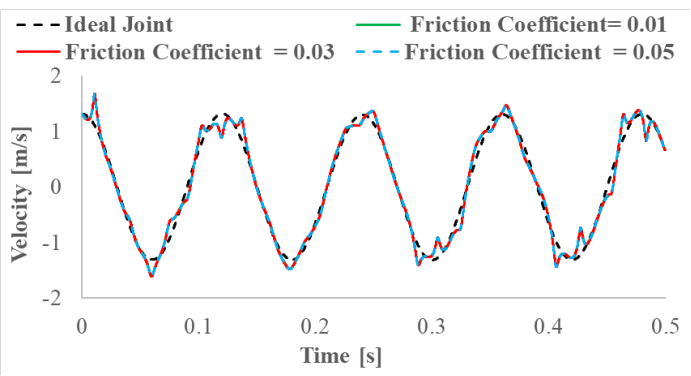

(b) Z-velocity.

Fig. 7: Velocity of the $1^{\text {st }}$ connecting rod.

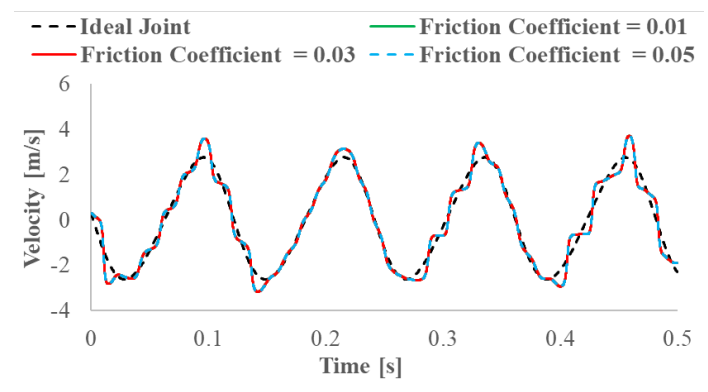

(a) X-velocity.

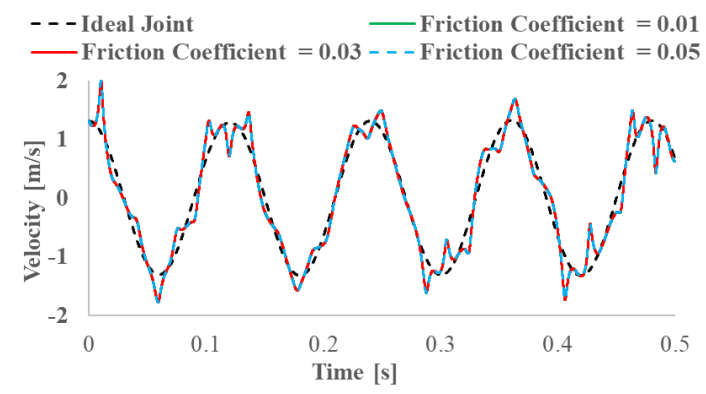

(b) Z-velocity.

Fig. 8: Velocity of the $2^{\text {nd }}$ connecting rod.

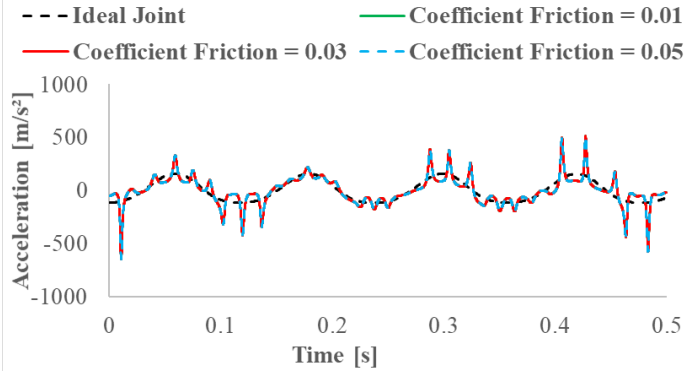

(a) X-acceleration.

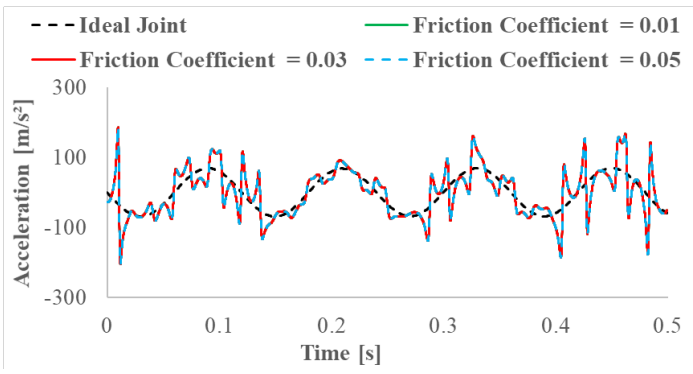

(b) Z-acceleration.

Fig. 9: Accelerations of the $1^{\text {st }}$ connecting rod .

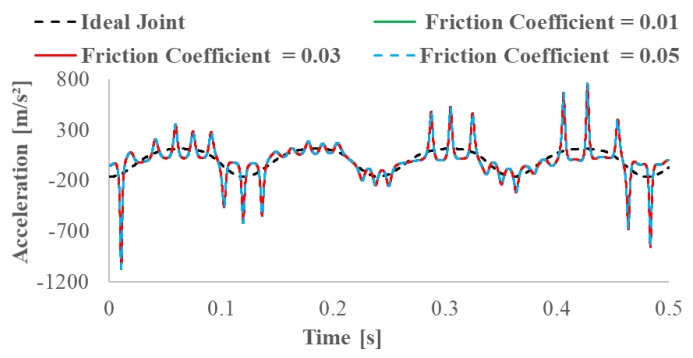

(a) X-acceleration.

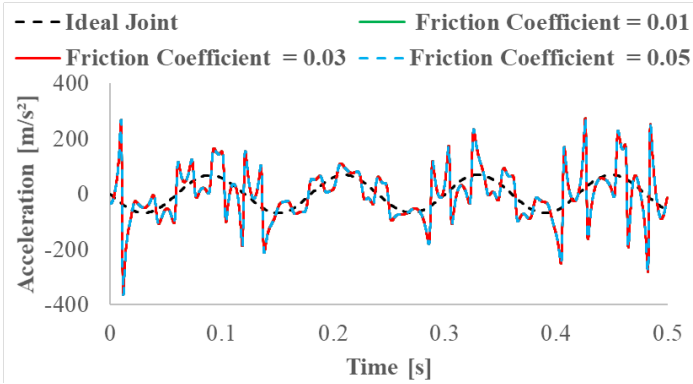

(b) Z-acceleration.

Fig. 10: Accelerations of the $2^{\text {nd }}$ connecting rod. 


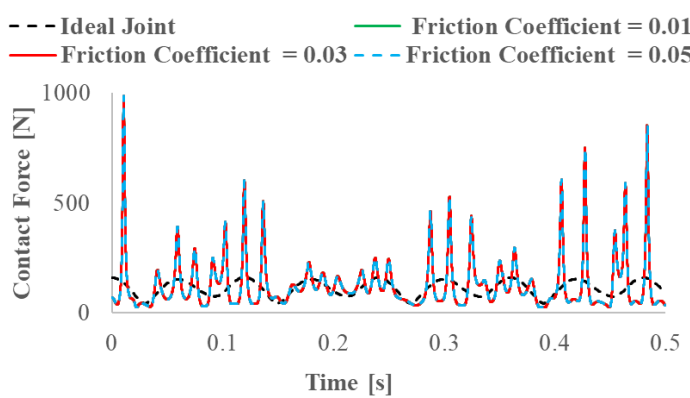

(a) Contact force $R_{1}$.

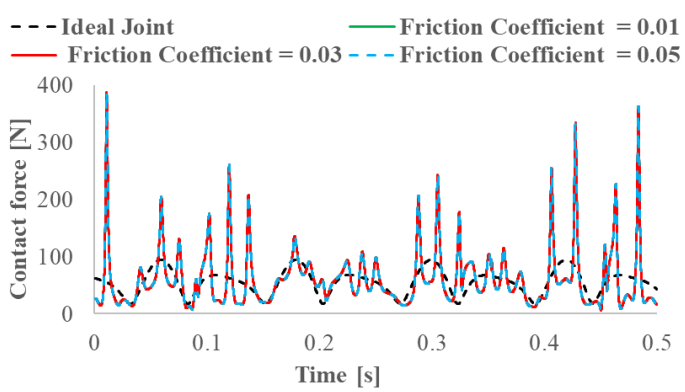

(b) Contact force $\mathrm{R}_{2}$.

Fig. 11: Contact force at different friction coefficient.

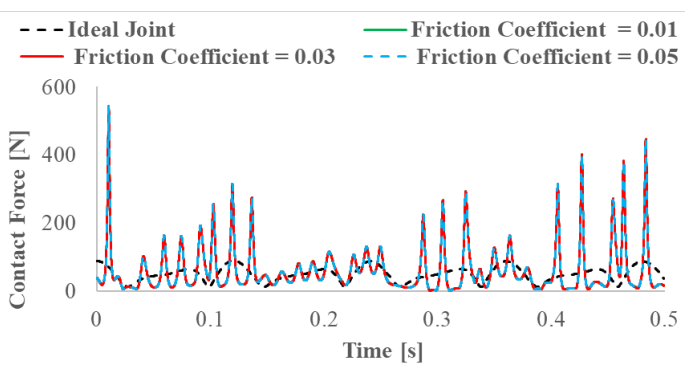

(a) Contact force $\mathrm{R}_{3}$.

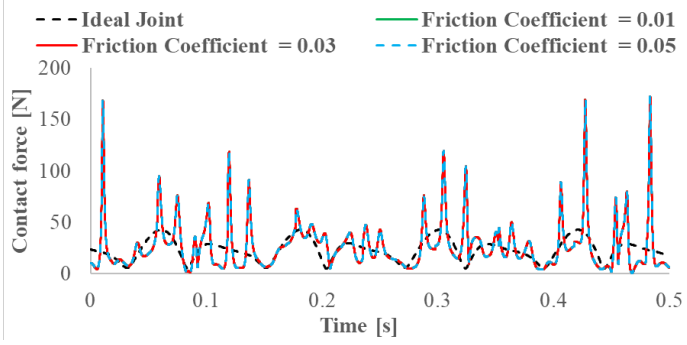

(b) Contact force $\mathrm{R}_{4}$.

Fig. 12: Contact force at different friction coefficient.

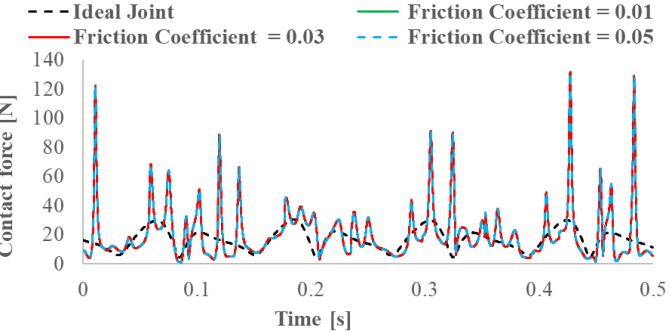

(a) Contact force $R_{5}$.

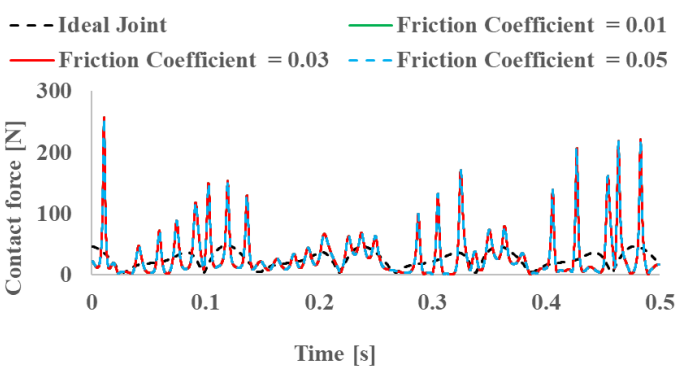

(b) Contact force $\mathrm{R}_{6}$.

Fig. 13: Contact force at different friction coefficient.

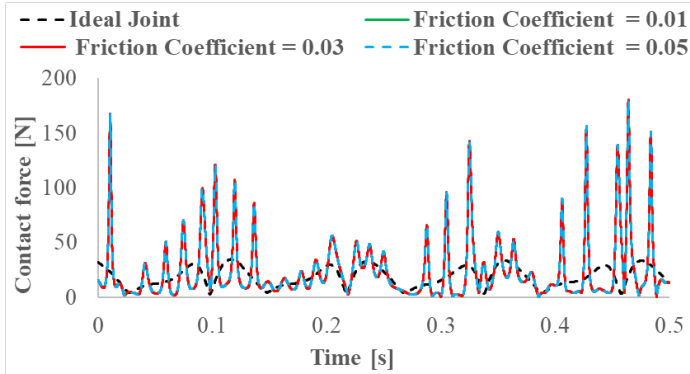

Fig. 14: Contact force $R_{7}$ at different friction coefficient.

From the simulation results demonstrated velocities, accelerations of two sliders, two connecting rod and the contact force in revolute clearance joints is not affected by friction which affecting by gap because friction coefficient increase from 0.01 to 0.05 , the graph of velocities, acceleration and contact force are the same each other. 


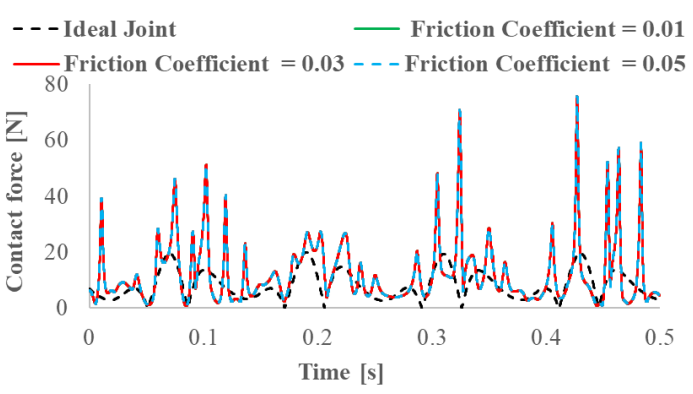

(a) Contact force $T_{1}$.

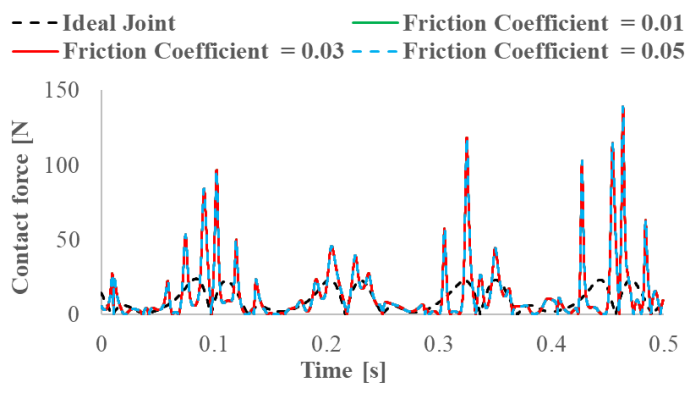

(b) Contact force $T_{2}$.

Fig. 15: Contact force at different friction coefficient.

\section{Conclusions}

This article has investigated the effects of clearances and friction on the dynamic responses of a slider-crank mechanism with two sliders. The model included a crank, two connecting rods, two sliders was designed using Solidworks. In the meanwhile, seven revolute clearance joints, two translational joints, the fiction coefficients and driving speed were set up by ANSYS.

The simulation results can be concluded that the friction has slightly affected while the clearance has significantly affected on the dynamics characteristics. Because the accelerations of two sliders were vibrated with the high peaks from when the journal collided into bearing at radius clearance is $0.25 \mathrm{~mm}$ and compared with ideal joints. The problem induced contact force with high peaks and oscillation unstable, which is close to reference [1, 3, 5]. In future work, the dynamic responses of the mechanism will be controlled to make a better stable system, the mathematic model of the mechanical systems will compare with experiment and simulation result.

The main contribution of this study is to propose a design and analyze for a two slider crank mechanism with regard to effect of friction and clearance. In addition, the results of this study are basic guide for designing and analyzing the dynamics, and from those results, we can monitoring how a change in velocity and acceleration of the system.

Acknowledgments: This research is funded by Vietnam National Foundation for Science and Technology Development (NAFOSTED) under grant number 107.01-2016.20.

\section{References}

[1] MA, J., L. QIAN, G. CHEN, M. LI, "Dynamic analysis of mechanical systems with planar revolute joints with clearance," Mechanism and Machine Theory, vol. 94, pp. 148-164, 2015.

[2] LI, Y., G. CHEN, D. SUN, Y. GAO, K. WANG, "Dynamic analysis and optimization design of a planar slider-crank mechanism with flexible components and two clearance joints," Mechanism and Machine Theory, vol. 99, pp. 37-57, 2016.

[3] BAI, Z. F., Y. SUN, "A study on dynamics of planar multibody mechanical systems with multiple revolute clearance joints," European Journal of Mechanics - A/Solids, vol. 60, pp. 95-111, 2016.

[4] HUANG, S.-C., T. P. DAO, "Design and Analysis of Flexible Slider Crank Mechanism," International Journal of Aerospace and Mechanical Engineering, vol. 8, pp. 836-843, 2014.

[5] WANG, X., G. LIU, S. MA, R. TONG, "Effects of restitution coefficient and material characteristics on dynamic response of planar multi-body systems with revolute clearance joint," Journal of Mechanical Science and Technology, vol. 31, pp. 587-597, 2017.

[6] BAI, Z. F., Y. ZHAO, "Dynamic behaviour analysis of planar mechanical systems with 
clearance in revolute joints using a new hybrid contact force model," International Journal of Mechanical Sciences, vol. 54, pp. 190-205, 2012.

[7] VAREDI, S. M., H. M. DANIALI, M. DARDEL, A. FATHI, "Optimal dynamic design of a planar slider-crank mechanism with a joint clearance," Mechanism and Machine Theory, vol. 86, pp. 191-200, 2015.

[8] ZHAO, B., Z.-N. ZHANG, C.-C. FANG, X.D. DAI, Y.-B. XIE, "Modeling and analysis of planar multibody system with mixed lubricated revolute joint," Tribology International, vol. 98, pp. 229-241, 2016.

[9] ZHAO, B. K., Y.-B ZHOU, Y.-B. XIE, "A new numerical method for planar multibody system with mixed lubricated revolute joint," International Journal of Mechanical Sciences, vol. 113, pp. 105-119, 2016.

\section{About Authors}

Ngoc Thai HUYNH received his Bachelor's Degree and Master Degree in Mechanical Engineering from the Ho Chi City University of Technology and Education, Vietnam, in 2008 and 2014, respectively. He worked as lecture in Dong Nai Technology University, Vietnam. He is currently a Ph.D. student in the National Kaohsiung University of Applied Sciences Taiwan, ROC. His interests include optimal systems design, kinematics and dynamics of Rigid and Flexible multi-body mechanism.

Thanh Phong DAO received his Bachelor's Degree in Mechanical Engineering from the Ho Chi Minh City University of Technology and Education, Vietnam in 2008. He received his Master and Ph.D Degree in Mechanical Engineering from the National Kaohsiung University of Applied Sciences, Taiwan, ROC, in 2011 and 2015, respectively. Currently, he is a researcher at the Institute for Computational Science, Ton Duc Thang University, Ho Chi Minh, Vietnam. His interests include compliant mechanism, bioinspiration, biomimetics, smart structure, precision machine, rehabilitation, sensor and actuator, prosthetics, soft computing, optimization algorithm.

Tuan Hai NGUYEN received his Bachelor's Degree and Master Degree in Mechanical Engineering from the Ho Chi City University of Technology and Education, Vietnam, in 2005 and 2011. He is currently a vice dean at faculty of Electrical, Electronic, Mechanical \& Construction in Dong Nai Technology University, Vietnam. His interests include robotics, kinematic and dynamic analytics, FEM, welding technology.

Hoang Nghien VU received his Bachelor's Degree in Mechanical Engineering from Lac Hong University, Vietnam in 2008. He is studying a master's degree program at Ho Chi Minh City University of Technology and Education and working as a lecture in Dong Nai Technology University, Vietnam. His interests include robotics, kinematic and dynamic analytics, control algorithm.

Le Quang Nhat HOANG received his Bachelor's Degree in Mechanical Engineering from the Ho Chi Minh City University of Industry, Vietnam in 2011. He is studying a master's degree program at Ho Chi Minh City University of Technology and Education and working as a lecture in Dong Nai Technology University, Vietnam. His interests include robotics, kinematic and dynamic analytics, control algorithm.

Ho NGUYEN received his Bachelor's Degree in Mechanical Engineering from the Ho Chi Minh City University of industrial, Vietnam in 2011. He received his Master Degree in Mechanical Engineering from the Ho Chi City University of Technology and Education, Vietnam in 2015. Currently, he is a lecturer at the Faculty of Electrical, Electronic, Mechanical \& Construction, Dong Nai Technology University, Vietnam. His interests include optimal systems design, injection mold, kinematics and dynamics of Rigid and Flexible multi-body mechanism.

"This is an Open Access article distributed under the terms of the Creative Commons Attribution License, which permits unrestricted use, distribution, and reproduction in any medium, provided the original work is properly cited (CC BY 4.0)." 